\title{
The time-dependent similarity solutions of boundary layer equations of Power-law fluids with non-isothermal surface
}

\author{
Muhammet Yurusoy \\ Department of Mechanical Engineering, Afyon Kocatepe University, Afyon, Turkey \\ Email address: \\ yurusoy@aku.edu.tr
}

\section{To cite this article:}

Muhammet Yurusoy. The Time-Dependent Similarity Solutions of Boundary Layer Equations of Power-Law Fluids with Non-Isothermal Surface. Applied and Computational Mathematics. Vol. 3, No. 5, 2014, pp. 235-239. doi: 10.11648/j.acm.20140305.17

\begin{abstract}
Unsteady, two dimensional boundary layer flows over a heated surface of power-law fluids are investigated. Surface temperature is assumed to have o power-law variation with the time and the distance. Similarity transformation is applied to the partial differential equation system with three independent variables is reduced into an ordinary differential equations systems. Numerical solutions of non-linear differential equations are found by using a finite difference scheme. Solutions are obtained for boundary layer flow velocity and thermal boundary layer profile. Effects of flow behavior index, Prandtl number, suction-injection parameter and surface temperature exponent with the time and the distance are outlined in the figures.
\end{abstract}

Keywords: Unsteady Flow, Power-Law Fluids, Non-Isothermal Surface

\section{Introduction}

The flow of boundary layer for non-Newtonian fluids over a moving surface has import engineering applications, for example metal or plastic extrusion, lubrication and heat exchangers etc. Yürüsoy [1] studied the similarity solution of a boundary layer on a stretched surface for a Power-Law fluid. By using a special similarity transformation, which was used also in this paper, he reduces the unsteady boundary layer equations to a non-linear ordinary differential equation system. Yürüsoy and Pakdemirli [2] treated the symmetry reductions of unsteady three dimensional boundary layer equations of non-Newtonian fluids by using Lie Group analysis. Acrivos et al.[3] examined the flow past a horizontal flat plate including heat transfer without dispersion term in the energy equation. Schowalter [4] investigated two and three dimensional boundary layer equation of power-law fluids. Chen [5] treated effect of suction-injection and magnetic field on convection heat transfer of power-law fluid over a stretching sheet. Ece [6] investigated free convection to power-law fluids from a vertical cone of variable surface temperature. Luna et al. [7] analyzed the case of conjugated heat transfer in circular ducts for a power-law fluid. Hassanien [8] considered the heat transfer in power-law fluid over a non-isothermal stretching sheet.
In recent years, Lamsaadi [9] investigated natural convection heat transfer in shallow horizontal rectangular enclosures uniformly heated from the side and filled with non-Newtonian power-law fluids. Mahmood et al. [10] investigated flow and heat transfer over a permeable sensor surface placed in a squeezing channel. Abel et al. [11,12] studied the flow of a power-law fluid due to a linearly stretching sheet and heat transfer characteristics using variable thermal conductivity in the presence of a nonuniform heat source/sink. They also considered the effects of thermal buoyancy and variable thermal conductivity on the MHD flow past a vertical stretching sheet.

In this paper, two-dimensional, unsteady boundary layer flow over a moving surface with suction or injection is analyzed. The problem of convection heat transfer to powerlaw fluid from a horizontal heated plate whose surface temperature has a power-law variation with the distance and the time is investigated in this study. Variable surface temperature have attracted many industrial applications may be represented by a suitable choice of power exponent. Momentum and energy equations are obtained and cast into non-dimensional form. By using a special similarity transformation [1], we reduce the unsteady boundary layer equations to a non-linear ordinary differential equation system. The ordinary differential equations are solved numerically by using a finite difference scheme. Effects of 
similarity solutions for the boundary layer velocity and thermal boundary layer profile and to obtain the effects of suction or injection parameter, flow behavior index, Prandtl number, and surface temperature exponent on heat flux are discussed.

\section{Governing Equations}

In this section, the problem of unsteady laminar boundary layer flow of a power-law fluid with thermophysical properties over a moving surface, with suction or withdrawal and blowing is treaded. The stress constitutive and heat flux equation for power-law fluids is expressed as [13]

$$
\begin{gathered}
\tau_{\mathrm{ij}}=-\mathrm{p} \delta_{\mathrm{ij}}+\mathrm{K}\left|\frac{1}{2} \mathrm{I}_{2}\right|^{(\mathrm{n}-1) / 2} \mathrm{e}_{\mathrm{ij}} \\
\mathrm{q}=-\mathrm{K}_{1}\left|\frac{1}{2} \mathrm{I}_{2}\right|^{\mathrm{m} / 2} \operatorname{grad}(\mathrm{T})
\end{gathered}
$$

Here $\tau_{\mathrm{ij}}$ are dimensional shear stress, $\mathrm{e}_{\mathrm{ij}}$ is strain rate, $\delta_{\mathrm{ij}}$ is Kronecker delta, $\mathrm{q}$ is dimensional heat flux, $\mathrm{I}_{2}$ is second invariant of strain-rate tensor, $\mathrm{K}$ is fluid consistency index, $\mathrm{K}_{1}$ is thermal conductivity, $\mathrm{T}$ is the temperature, $\mathrm{p}$ is pressure, $\mathrm{n}$ and $\mathrm{m}$ are superscripts the non-Newtonian behavior in the flow and heat transfer, respectively.

A stream function is defined according to

$$
u=\frac{\partial \psi}{\partial y}, \quad v=-\frac{\partial \psi}{\partial x}
$$

Here $\mathrm{x}$ and $\mathrm{y}$ are coordinates measuring distance along the plate and normal to it, respectively with $u$ and $v$ he velocity components in $\mathrm{x}$ and $\mathrm{y}$ coordinates. A tedious straightforward algebras yields the unsteady non-dimensional momentum and energy equations

$$
\begin{aligned}
& \frac{\partial^{2} \psi}{\partial \mathrm{t} \partial \mathrm{y}}+\frac{\partial \psi}{\partial \mathrm{y}} \frac{\partial^{2} \psi}{\partial \mathrm{x} \partial \mathrm{y}}-\frac{\partial \psi}{\partial \mathrm{x}} \frac{\partial^{2} \psi}{\partial \mathrm{y}^{2}}=\mathrm{n}\left|\frac{\partial^{2} \psi}{\partial \mathrm{y}^{2}}\right|^{\mathrm{n}-1} \frac{\partial^{3} \psi}{\partial \mathrm{y}^{3}} \\
& \frac{\partial \mathrm{T}}{\partial \mathrm{t}}+\frac{\partial \psi}{\partial \mathrm{y}} \frac{\partial \mathrm{T}}{\partial \mathrm{x}}-\frac{\partial \psi}{\partial \mathrm{x}} \frac{\partial \mathrm{T}}{\partial \mathrm{y}}=\frac{1}{\operatorname{Pr}} \frac{\mathrm{d}}{\mathrm{dy}}\left[\left|\frac{\partial^{2} \psi}{\partial \mathrm{y}^{2}}\right|^{\mathrm{m}} \frac{\partial \mathrm{T}}{\partial \mathrm{y}}\right]
\end{aligned}
$$

which are subject to following boundary conditions:

$$
\begin{aligned}
& \frac{\partial \psi}{\partial y}(x, 0, t)=U(x, t), \frac{\partial \psi}{\partial x}(x, 0, t)=-V(x, t), \frac{\partial \psi}{\partial y}(x, \infty, t)=0 \\
& T(x, 0, t)=S(x, t), T(x, \infty, t)=0
\end{aligned}
$$

where $t$ is time. $S(x, t)$ is surface temperature function, $U(x, t)$ is the moving surface velocity, $\mathrm{V}(\mathrm{x}, \mathrm{t})$ is the suction or withdrawal and blowing velocity of the porous surface.

The non-dimensional parameters are related to their dimensional ones through the following relations:

$$
\begin{aligned}
& \hat{x}=x L, \hat{y}=L y \operatorname{Re}^{-\frac{1}{n+1}}, \hat{t}=\frac{t L}{U_{0}}, \hat{u}=U_{0} u, \hat{v}=U_{0} v R^{-\frac{1}{n+1}}, T=\frac{\hat{T}-T_{\infty}}{T_{r}-T_{\infty}} \\
& \operatorname{Re}=\frac{\rho U_{0}^{2-n} L^{n}}{K}, \operatorname{Pr}=\frac{U_{0}^{1-m} L^{1+m} \operatorname{Re}^{\frac{m+1}{n+1}}}{K_{1}}, \hat{U}=U_{0} U, \hat{V}=U_{0} \operatorname{Re}^{-\frac{1}{n+1}}, \hat{S}=\left(T_{r}-T_{\infty}\right) S+T_{\infty}
\end{aligned}
$$

Here $\operatorname{Pr}$ is modified Prandtl number, Re is generalized Reynold number, $\mathrm{L}$ an $\mathrm{U}_{0}$ length of horizontal surface, average velocity, respectively. $\rho$ is density of the fluid. $T$ is temperature, $T_{r}$ is the any reference temperature and $T_{\infty}$ is the ambient temperature $\left(\mathrm{T}_{\mathrm{w}}>\mathrm{T}_{\infty}\right)$.

Similarity variables for equations (4), (5) and (6) are introduced as

$$
\begin{gathered}
\xi=y x^{a_{1}} t^{a_{2}}, \psi=x^{a_{3}} t^{a_{4}} R(\xi), T=x^{a_{5}} t^{a_{6}} L(\xi), \\
U=\lambda x^{a_{7}} t^{a_{8}}, V=\gamma a_{3} x^{a_{9}} t^{a_{10}}, S=x^{a_{11}} t^{a_{12}}
\end{gathered}
$$

where $a_{1}, a_{2}, a_{3}, a_{4}, a_{5}, a_{6}, a_{7}, a_{8}, a_{9}, a_{10}, a_{11}, a_{12}$ are constant to be determined for given values of the Power-Law index $n$.

Substituting equation (10) into equations (4) and (5), the boundary layer equations take the following forms:

$$
\begin{aligned}
&\left(\mathrm{a}_{4}+\mathrm{a}_{2}\right) \mathrm{R}^{\prime}+\mathrm{a}_{2} \xi \mathrm{R}^{\prime \prime}+\left(\mathrm{a}_{3}+\mathrm{a}_{1}\right) \mathrm{x}^{\mathrm{a}_{3}+\mathrm{a}_{1}-1} \mathrm{t}^{\mathrm{a}_{2}+\mathrm{a}_{4}+1} \mathrm{R}^{\prime 2}-\mathrm{a}_{3} \mathrm{x}^{\mathrm{a}_{3}+\mathrm{a}_{1}-1} \mathrm{t}^{\mathrm{a}_{2}+\mathrm{a}_{4}+1} \mathrm{RR}^{\prime \prime} \\
&= \mathrm{nx} \mathrm{x}^{(\mathrm{n}-1)\left(2 \mathrm{a}_{1}+\mathrm{a}_{3}\right)+2 \mathrm{a}_{1}} \mathrm{t}^{(\mathrm{n}-1)\left(2 \mathrm{a}_{2}+\mathrm{a}_{4}\right)+2 \mathrm{a}_{2}+1}\left|\mathrm{R}^{\prime \prime}\right|^{\mathrm{n}-1} \mathrm{R}^{\prime \prime \prime} \\
& a_{6} \mathrm{~L}^{\prime}+\mathrm{a}_{2} \xi \mathrm{L}^{\prime}+\mathrm{a}_{5} \mathrm{x}^{\mathrm{a}_{3}+\mathrm{a}_{1}-1} \mathrm{t}^{\mathrm{a}_{2}+\mathrm{a}_{4}+1} \mathrm{R}^{\prime} \mathrm{L}-\mathrm{a}_{3} \mathrm{x}^{\mathrm{a}_{3}+\mathrm{a}_{1}-1} \mathrm{t}^{\mathrm{a}_{2}+\mathrm{a}_{4}+1} \mathrm{~L}^{\prime} \mathrm{R} \\
&=\frac{\mathrm{d}}{\mathrm{d} \xi}\left[\left|\mathrm{R}^{\prime \prime}\right|^{\mathrm{m}} \mathrm{L}^{\prime}\right] \mathrm{x}^{\mathrm{m}\left(2 \mathrm{a}_{1}+\mathrm{a}_{3}\right)+2 \mathrm{a}_{1}} \mathrm{t}^{\mathrm{m}\left(2 \mathrm{a}_{2}+\mathrm{a}_{4}\right)+2 \mathrm{a}_{2}+1}
\end{aligned}
$$

Requiring that new equations remain invariant under these transformations leads to the conditions

$$
\begin{aligned}
& \mathrm{a}_{3}+\mathrm{a}_{1}=1, \mathrm{a}_{2}+\mathrm{a}_{4}=-1,(\mathrm{n}-1)\left(2 \mathrm{a}_{1}+\mathrm{a}_{3}\right)+2 \mathrm{a}_{1}=0, \\
& (\mathrm{n}-1)\left(2 \mathrm{a}_{2}+\mathrm{a}_{4}\right)+2 \mathrm{a}_{2}+1=0 \\
& \mathrm{~m}\left(2 \mathrm{a}_{1}+\mathrm{a}_{3}\right)+2 \mathrm{a}_{1}=0, \mathrm{~m}\left(2 \mathrm{a}_{2}+\mathrm{a}_{4}\right)+2 \mathrm{a}_{2}+1=0
\end{aligned}
$$

Solution of equations (11) for the constants $a_{1}, a_{2}, a_{3}, a_{4}, a_{5}$, $\mathrm{a}_{6}, \mathrm{a}_{7}, \mathrm{a}_{8}, \mathrm{a}_{9}, \mathrm{a}_{10}, \mathrm{a}_{11}, \mathrm{a}_{12}$ and $\mathrm{m}$ yields

$$
\begin{aligned}
& \mathrm{a}_{1}=\frac{1-\mathrm{n}}{\mathrm{n}+1}, \mathrm{a}_{2}=\frac{\mathrm{n}-2}{\mathrm{n}+1}, \mathrm{a}_{3}=\frac{2 \mathrm{n}}{\mathrm{n}+1}, \mathrm{a}_{4}=\mathrm{a}_{10}=\frac{1-2 \mathrm{n}}{\mathrm{n}+1}, \mathrm{a}_{9}=\frac{\mathrm{n}-1}{\mathrm{n}+1} \\
& \mathrm{~m}=\mathrm{n}-1, \mathrm{a}_{7}=1, \mathrm{a}_{8}=-1, \mathrm{a}_{11}=\mathrm{a}_{5}, \mathrm{a}_{12}=\mathrm{a}_{6}
\end{aligned}
$$


$\mathrm{a}_{5}$ and $\mathrm{a}_{6}$ are arbitrary constants. Substituting equations (12) and (8) into equations (4) and (5) we finally obtain

$$
\begin{aligned}
& \frac{\mathrm{n}-2}{\mathrm{n}+1} \xi \mathrm{R}^{\prime \prime}-\mathrm{R}^{\prime}\left(1-\mathrm{R}^{\prime}\right)-\frac{2 \mathrm{n}}{\mathrm{n}+1} \mathrm{RR}^{\prime \prime}=\mathrm{n}\left|\mathrm{R}^{\prime \prime}\right|^{\mathrm{n}-1} \mathrm{R}^{\prime \prime \prime} \\
& \frac{\mathrm{n}-2}{\mathrm{n}+1} \xi \mathrm{L}^{\prime}+\mathrm{L}\left(\mathrm{a}_{6}+\mathrm{a}_{5} \mathrm{R}^{\prime}\right)-\frac{2 \mathrm{n}}{\mathrm{n}+1} \mathrm{~L}^{\prime} \mathrm{R}=\frac{1}{\operatorname{Pr}} \frac{\mathrm{d}}{\mathrm{d} \xi}\left(\left|\mathrm{R}^{\prime \prime}\right|^{\mathrm{n}-1} \mathrm{~L}^{\prime}\right)
\end{aligned}
$$

with the boundary conditions of

$$
\mathrm{R}(0)=-\gamma, \mathrm{R}^{\prime}(0)=\lambda, \mathrm{L}(0)=1, \mathrm{R}^{\prime}(\infty)=0, \mathrm{~L}(\infty)=0
$$

For this equations, when $n=1$, the fluid is Newtonian, $n<0$ is corresponds to the Pseudo-Plastic fluid, $n>0$ is corresponds to the Dilatant fluid. Equations (13) and (14) define a set of coupled second-order non-linear differential equations for $\mathrm{R}$ and $\mathrm{L}$ subject to the boundary conditions (15) were solved numerically using finite difference scheme.

Generalized local Nusselt number is defined as

$$
\mathrm{Nu}=\frac{\mathrm{q}_{\mathrm{w}} \mathrm{L}^{\mathrm{n}}}{\mathrm{K}_{1}\left(\mathrm{~T}_{\mathrm{w}}-\mathrm{T}_{\infty}\right) \mathrm{V}^{\mathrm{n}-1}}
$$

where $\mathrm{q}_{\mathrm{w}}$ is heat flux. Using definitions given by equation (2) and the others parameters it may be shown that

$$
N u R e^{-\frac{n}{n+1}}=-x \frac{(n-1)+a_{5}\left(a_{1}+1\right)}{n+1} \frac{(1-2 n)+a_{6}(n+1)}{n+1}|R(0)|^{n-1} L^{\prime}(0)
$$

By using a special finite difference scheme, equations (13) and (14) are integrated subject to the boundary conditions (15).

\section{Results and Discussion}

Figure 1 shows temperature profile for generalized Prandtl number which were taken in the range from 1 to 100 and the values of the parameters were $a_{5}=a_{6}=1 . a_{5}$ and $a_{6}$ are the surface temperature exponents with the distance and the time respectively. Temperature magnitude increases with reducing generalized Prandtl number. Figure 2 displays the variation of temperature for three different values $a_{6}$. Temperature increases with decreases surface temperature exponent with the time $a_{6}$. Variation of temperature is shown for different $a_{5}$ values in Figure 3. Increasing surface temperature exponent with the distance $a_{5}$ lowers temperature. In Figure 4, velocity profile is plotted for power-law indexes n. The boundary layers are qualitatively different for $\mathrm{n}<1$ (shear thinning fluid) and $n>1$ (shear thickening fluid) cases. For shear thinning fluid $(\mathrm{n}<1)$, the velocity increases with increasing $n$, but in the shear thickening $(n>1)$, velocity increases with decreasing $\mathrm{n}$ in the range of $\xi=1$ to $\xi=5$. Figure 5 shows effects of suction, injection parameter and no penetration for velocity profile. Velocity boundary layer thickness increases for injection, and decreases for suction cases are displayed in Figure 5. Effects of suction/injection parameters on temperature profiles are shown in Figure 6. For suction case, thickness of the thermal boundary layer decreases, whereas for injection case increases the thickness of the thermal boundary layer. Figure 7 and 8 display the variation of $\mathrm{NuRe} \mathrm{e}^{-\frac{\mathrm{n}}{\mathrm{n}+1}}$ for Prandtl number and the surface temperature exponent $\mathrm{a}_{6}$ and $\mathrm{a}_{5}$. Figure 7 shows the local Nusselt number increases with increasing values of the power-law index $n$ and values of Prandtl number. But, the local Nusselt number decreases with increasing surface temperature exponent $a_{6}$. Variation of term $a_{5}$ is shown in Figure 8. The local Nusselt number increases with increasing power-law index $n$ for values of $a_{5}=1$ and $a_{5}=0$ and increases with increasing values of Prandtl number, but a reverse effect is observed for $a_{5}=-1$, $\operatorname{Pr}=10$ and $\operatorname{Pr}=100$.

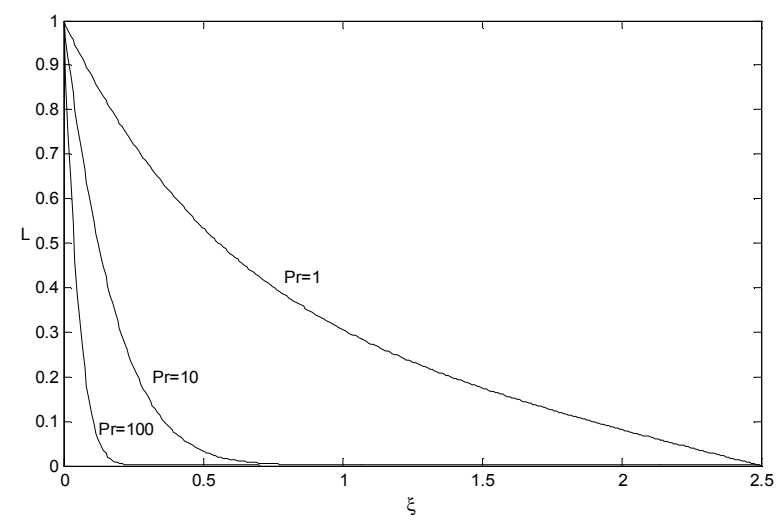

Figure 1. Temperature profiles for $a_{5}=a_{6}=1, \lambda=1, \gamma=0$ and $n=0.5$

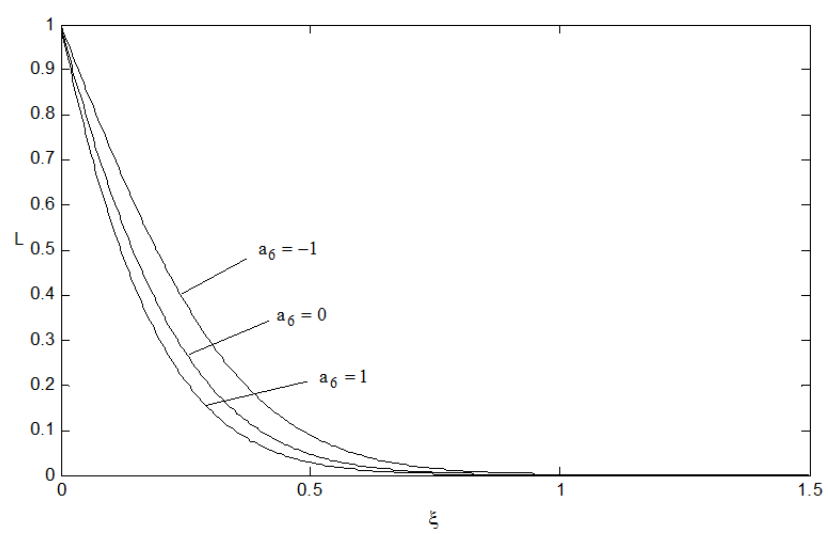

Figure 2. Temperature profiles for $a_{5}=1, \operatorname{Pr}=10, \lambda=1, \gamma=0$ and $n=0.5$

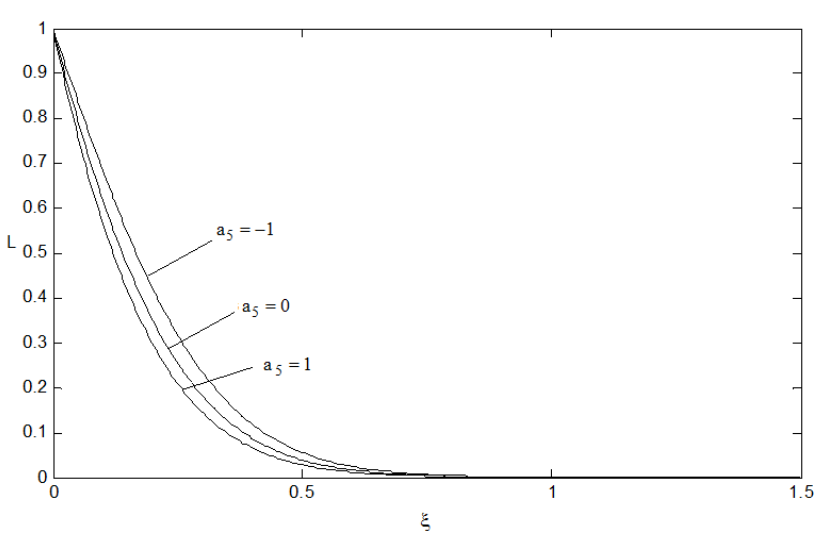

Figure 3. Temperature profiles for $a_{6}=1, \operatorname{Pr}=10, \lambda=1, \gamma=0$ and $n=0.5$ 


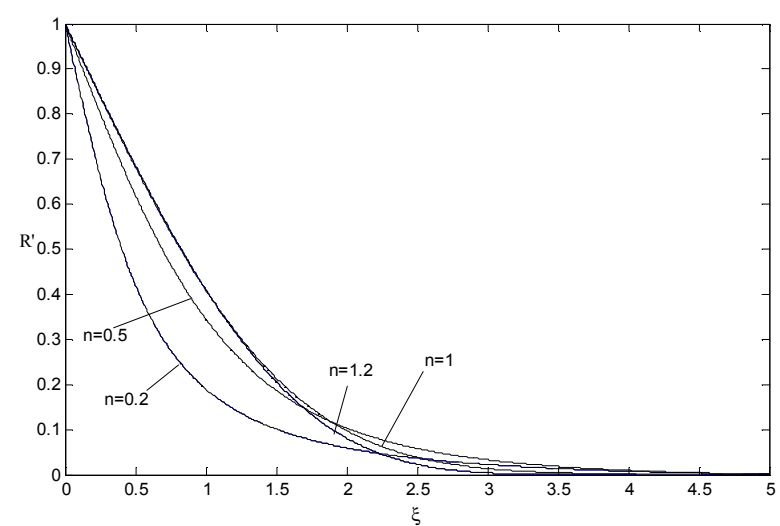

Figure 4. Velocity profiles for $a_{5}=a_{6}=1, \operatorname{Pr}=10, \lambda=1$ and $\gamma=0$

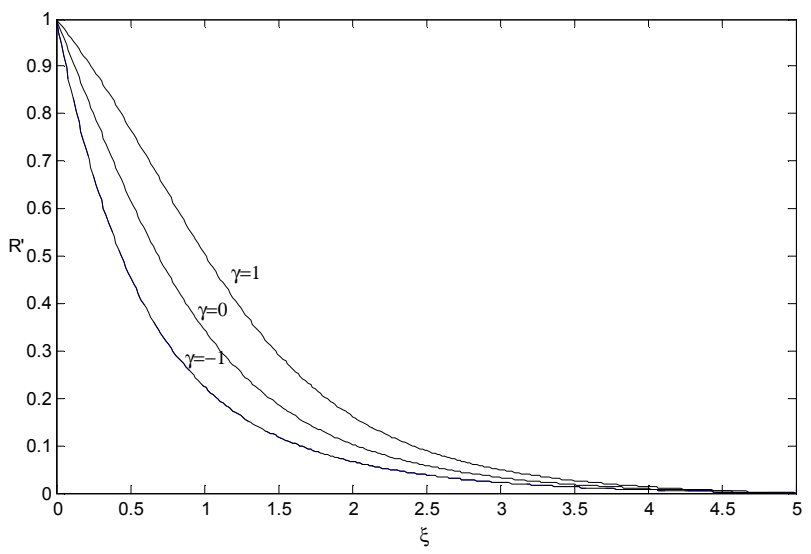

Figure 5. Velocity profiles for $a_{5}=a_{6}=1, \operatorname{Pr}=10, \lambda=1$ and $n=0.5$

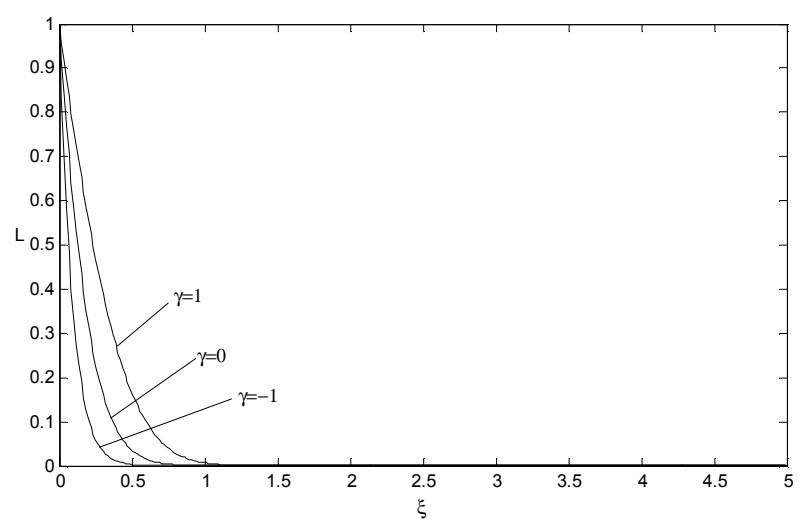

Figure 6. Temperature profiles for $a_{5}=a_{6}=1, \operatorname{Pr}=10, \lambda=1$ and $n=0.5$

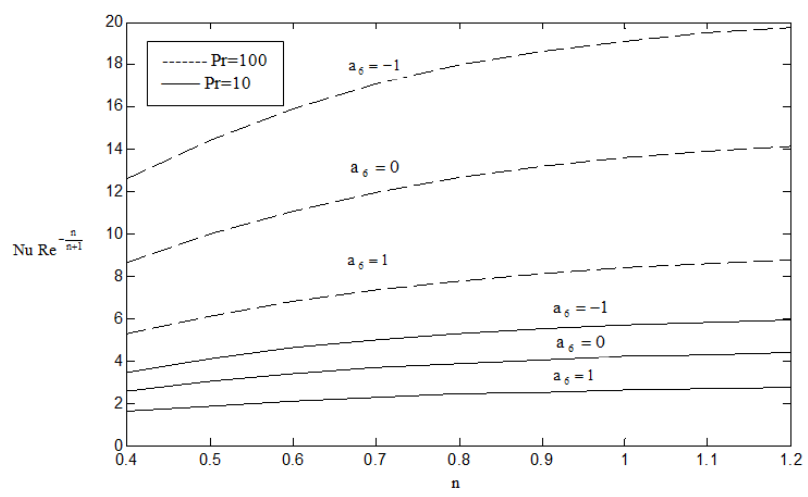

Figure 7. Variation of the local Nusselt number profiles for $a_{5}=1, \lambda=1$ and $\gamma=0$

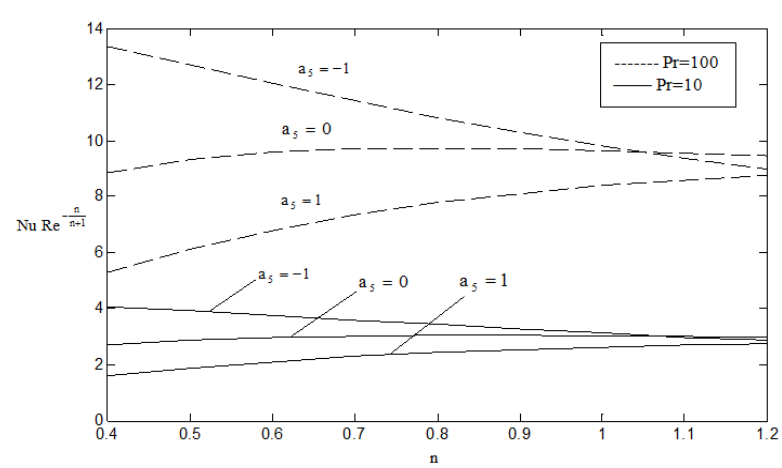

Figure 8. Variation of the local Nusselt number profiles for $a_{6}=1, \lambda=1$ and $\gamma=0$

\section{Conclusions}

Similarity solutions of boundary layer equations for convection to non-Newtonian power-law fluid form horizontal plate whose temperature have a power-law variation with the distance and the time were investigated. Magnitude of the temperature profile was found to decrease with increasing Prandtl number, $\mathrm{a}_{5}$ and $\mathrm{a}_{6}$. The momentum boundary layer thickness increases with increasing $\mathrm{n}$ for shear thinning fluid $(\mathrm{n}<1)$, but in the shear thickening $(\mathrm{n}>1)$, boundary layer thickness decreases with increasing $\mathrm{n}$ beyond $\xi=1$. Flow behavior index n, surface temperature exponents $\mathrm{a}_{5}$ and $\mathrm{a}_{6}$ and Prandtl number have profound on local Nusselt number.

\section{References}

[1] Yürüsoy M., 2006, Unsteady boundary layer flow of powerlaw fluid on stretching sheet surface, Internat. J. Engrg. Sci., $44,325-332$

[2] Yürüsoy M., Pakdemirli M., 1997, Symmetry reduction of unsteady threedimensional boundary layers of some nonNewtonian fluids., Internat. J. Engrg. Sci., 35, 731-740.

[3] Acrivos A., Shah M.J., Petersen E.E., 1960, Momentum and heat transfer in laminar boundary layer ows of non-Newtonian uids past external surface, A. I. Ch. E. J1., 6, 312-317

[4] Schowalter W.R.,1960, The application of boundary-layer theory to power-law pseudoplastic fluids: similarity solutions, AIChE J., 6, 25-28.

[5] Chen C.H., 2008, Effects of magnetic field and suction/injection on convection heat transfer of nonNewtonian power-law fluids past a power-law stretched sheet with surface heat flux, Int. J. Thermal Sci., 47, 954-961.

[6] Ece C. E., 2001, Free convection to power-law fluids from a vertical cone of variable surface temperature. 25, 1221-1232.

[7] Luna N, Mendez F, Trevino C., 2002, Conjugated heat transfer in circular ducts with a power-law laminar convection fluid flow., Int. J. Heat Mass Trans., 45, 655-666.

[8] Hassanien I.A., Abdullah A.A., Gorla R.S.R., 1998, Flow and heat transfer in a power-law fluid over a nonisothermal stretching sheet., 28, 105-116. 
[9] Lamsaadi M., Naïmi M., Hasnaoui M., 2006, Natural convection heat transfer in shallow horizontal rectangular enclosures uniformly heated from the side and filled with nonNewtonian power law fluids., 47, 2535-2551.

[10] Mahmood M., Asghar S., Hossain, M.A., 2007, Squeezed flow and heat transfer over a porous surface for viscous fluid., Heat Mass Transfer, 44, 165-173.

[11] Abel M.S., Datti P.S., Mahesha N., 2009, Flow and heat transfer in a power-law fluid over a stretching sheet with variable thermal conductivity and non-uniform heat source., Int. J. Heat Mass Trans., 52, 2902-2913.
[12] Abel M.S,, Siddheshwar P,G,, Mahesha N., 2009, Effects of thermal buoyancy and variable thermal conductivity on the MHD flow and heat transfer in a power-law fluid past a vertical stretching sheet in the presence of a non-uniform heat source., 44, 1-12.

[13] Shvets Y.I.,Vishnevvskiy V.K., 1987, Effect of dissipation on convection heat transfer in flow of non-Newtonian fluid. Heat Transfer-Soviet Research, 19, 38-43. 